\title{
Dynamic Capacity Withholding Assessment by Considering the Static Limits of the Transmission Network and the Maintenance Problem of the Transmission System
}

\author{
${ }^{1}$ Seyed Mostafa Tabatabaei, ${ }^{2}$ Hossein Tahamifard, ${ }^{3}$ Hamidreza Abbasi fordoei \\ Tehran Regional Electric Company, Tehran, Iran \\ ${ }^{1}$ sm.tabatabaei1112@gmail.com \\ 2h.tahamy@gmail.com \\ ${ }^{3}$ Hamidrezaabbasi1365@gmail.com
}

\begin{abstract}
One of the important issues in the major instantaneous power market is the formation of groups based on physical collusion and preventing the supply of electricity in the market. Productive units with the formation of collusive groups will ultimately lead to increase the price of wholesale electricity market. The strategic repair of production units and the transmission network can be collateralized and eventually increase the price of the electricity market. In this paper, a new index for evaluating the physical collusion of manufacturers is proposed, taking into account the limits of production and transmission and strategic maintenance, and is tested on the network of 30 and 118 buses of the IEEE.
\end{abstract}

\section{Introduction}

In this section, a new modeling is proposed to examine the physical collusion of manufacturers through strategic repairs. Also, the previously proposed indexes are redefined to be used to analyze collusion in network conditions, with consideration for generation compliant repairs, as well as scheduling generation and transmission repairs in multi-polar markets. In this context, the concept of strategic maintenance is explained and, in the future, the capacity constraint is monitored in the presence of scheduled production repairs bound to the security constraints.

Then, by modeling the scheduling of simultaneous repairs of production and transmission, the effect of repairs on the transmission network is also considered. To illustrate the concept of strategic maintenance, we consider two manufacturers. In the market, manufacturers struggle to make more profit. For this reason, the competition of each producer can be simulated by a reaction function (Fig. 1). The functions of reaction react to the optimal strategies of each manufacturer. Based on the concept of game theory, the market balance point derived from the intersection of these functions. In fact, at this point, each vendor will maximize its competitors' behavior.

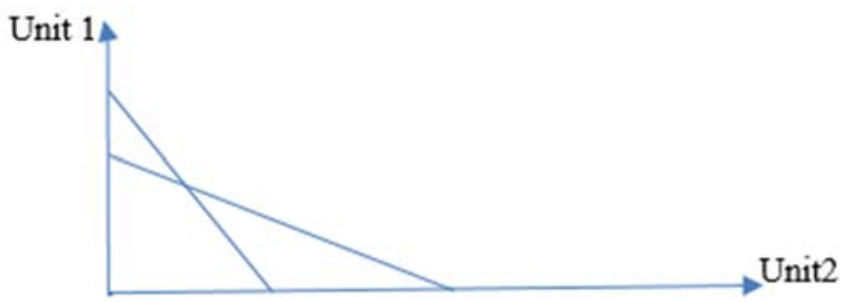

Fig.1. Reaction Function for 2 Producers

Manufacturers' decisions on maintenance planning are affected in one or more periods of time by their availability at other time periods. Indeed, manufacturers should specify their maintenance plans for several weeks, with different constraints. One of the complexities of this issue is the dependence of time periods. In fact, a producer can do repairs in a period of time to gain more profit by attending the market at other time periods. It can also put its units in a way that repairs will increase prices in different periods and will benefit more from the collaborative team. The physical collusion of manufacturers has been reported through repair planning at various markets in the world electricity market, but its modeling is based on physical collusion between manufacturers, especially in the presence of system security constraints. The problem solving levels are as follows: 


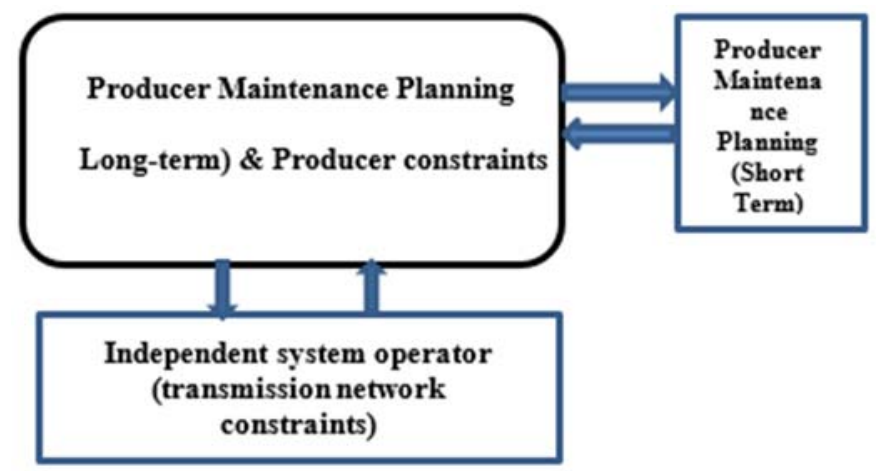

Fig.2. Problem solving levels

At the first level, manufacturers are optimizing their profits by choosing production strategies as well as repairs. On the second level, the independent user of the social welfare system maximizes the system constraints. In this case, the strategies of the manufacturers may change due to the security of the system constraints. This is a matter of weekly or weekly scheduling horizons for several time periods (weekly or monthly). These planning horizons are considered as planning horizons for long-term repairs, and together with the limits of entry and exit of units and the constraints of the transmission network, it limits the build-up of collusion in the power system. Birth units can also be repaired on several hour horizons, which will be discussed 24 hours a day for the network's transmission and logistics constraints 24 hours a day.[1-43]

This paper is divided as follows: Section 2 presents the model of wholesale electricity market as spot markets using the SFE model. In section3, the standard networks, 30 and 118 buses-IEEE by Maintenance Problem of the GenCos evaluated and the groups susceptible to collusion are listed. In section 4, Repair and maintenance of the transmission network has also been added to the problem. Conclusions from numerical studies and their comparison are presented in Section 5.

\section{Electricity Market Model}

It is assumed that in the market $I$ is the unit of production and the number of producers is equal to $F$. In addition, the maintenance cost per unit is assumed to be constan $C_{i, t}^{m g}$ and the cost of production is as follows:

$C_{i, t}^{g g}=0.5 a_{i, t} q_{i, t}{ }^{2}+b_{i, t} q_{i, t}$

In the above equation, $i$ is the index of production units, $t$ is the index of time periods, $C_{i, t}^{g g}$ is the unit production cost in shine $i$ and the time period $t, q_{i, t}$ is the unit production in shine $i$ and the time period $t, a_{i, t}$ is the slope of the unitary marginal cost function in shine $i$, and The time period $t$ and $b_{i, t}$ is the width of the origin the unitary marginal cost in time $i$ and time $t$. Also, consumption in shine $j$, in time $t$ is equal to:

$\lambda_{j, t}=-\alpha_{j, t} y_{j, t}+\beta_{j, t}$

In the above relation, $j$ is the index of the production units, $\lambda_{j, t}$ is the price of the bus $j$ and the time period $t$, $y_{j, t}$ is consumption in the bus $j$ and the period $t, \alpha_{j, t}$ is the inverse load slope of the load in the bus $j$ and the time period $t$ and $\beta_{j, t}$ is the width of the inverse function of the demand in the bus $j$ and the time period $t$. In this study, transmission network losses are neglected and the DC distribution approximation is used to model the transmission network. 
The objective function of optimizing the profit of each producer is as follows:

$$
\begin{aligned}
& \max \Omega_{f}=\sum_{t=1}^{24} \sum_{i=1}^{N}\left(\lambda_{i, t} q_{i, t}-0.5 a_{i, t} q_{i, t}^{2}-u_{i, t} c_{i, t}^{m g}\right) \\
& \text { S.t. } q_{i, t}^{\min }\left(1-u_{i, t}\right) \leq q_{i, t} \leq q_{i, t}^{\max }\left(1-u_{i, t}\right) \\
& \sum_{t=1}^{24} u_{i, t}=X_{i} \\
& u_{i, t}-u_{i,(t-1)} \leq u_{i,\left(t+X_{i}-1\right)}
\end{aligned}
$$

In the above relations, $f$ is the producer-related. $u_{i, t}$ index shows the binary decision variable for planning unit repairs in the bus $i$ and the time period $t$, which one indicates a unit in repairs, and zero indicates that the unit is being produced, $X_{i}$ is the number of required time periods in the bus $i$ for repairs, $N$ is the number of units, and $q_{i, t}^{\min }, q_{i, t}^{\max }$ are the minimum and maximum power constants in the bus $i$ and the time period $t$. Based on the relationships (3), each producer optimizes his profit function by choosing his own decision making variables. According to (4), if the unit is in repair, its production is zero and the requirement (5) will make repairs of each unit equal to the number of required time periods of the unit and the constraint (6) of the continuity in the courses Shows repairs of each unit. Regarding manufacturer's production and repair strategies, the independent operator of the system optimizes social welfare in accordance with the system constraints.

$$
\begin{aligned}
& \max S W= \\
& \sum_{t=1}^{24} \sum_{j=1}^{J}\left(-0.5 \alpha_{j, t} y_{j, t}^{2}+\beta_{j, t} y_{j, t}\right) \\
& -\sum_{t=1}^{24} \sum_{i=1}^{N}\left(0.5 a_{i, t} q_{i, t}^{2}+b_{i, t} q_{i, t}+u_{i, t} c_{i, t}^{m}\right) \\
& S . t . \sum_{i=1}^{N} q_{i, t}=\sum_{j=1}^{J} y_{j, t} \\
& \sum_{i=1}^{N}\left(q_{i, t}^{\max }\left(1-u_{i, t}\right)-q_{i, t}\right) \geq R_{t}^{\min } \\
& y_{j, t}^{\min } \leq y_{j, t} \leq y_{j, t}^{\max } \\
& -F_{t} \leq S\left(q_{t}-y_{t}\right) \leq F_{t}
\end{aligned}
$$

In the above relations, $R_{t}^{\min }$ is the minimum reserve requirement for the time period $t, y_{j, t}^{\max } y_{j, t}^{\min }$ are the maximum and minimum consumption and load constraints in the bus $j$ in the period $t, y_{t}$ is the consumption vector in the period $t, \mathrm{q}_{\mathrm{t}}$ is the production vector in the time period $t$, and $F_{t}$ is the constraint vector in the period $t$.

By solving the equation (7), the market equilibrium point is determined, and the amount of production per unit, the consumption of each time and price per buses is obtained. Constraints (8) and (9), respectively, represent the balance between production and consumption, and the minimum system reservation required. Also, the constraint (10) is related to the limits of load usage and shows (11) the DC load distribution in the vector. 
Since the transmission network also needs maintenance planning, the transmission companies will also provide their own repair program to the independent operator of the system and examine the independent operator of the system of programs of manufacturers and transmission companies simultaneously. Since the transmission company does not have market power, it only tries to reduce its maintenance costs. The issue of optimizing the transfer company is as follows:

$$
\begin{gathered}
\min \sum_{t=1}^{24} \sum_{l=1}^{L} c_{l, t}^{m l}\left(1-V_{l, t}\right) \\
\sum_{t=1}^{24} v_{i, t}=W_{l} \\
v_{i, t}-v_{i,(t-1)} \leq v_{i,\left(t+X_{i}-1\right)}
\end{gathered}
$$

In the above relations, $l$ is the index of the network lines, $c_{l, t}^{m l}$ is the cost of line $l$ repairs over time $t, v_{i, t}$ is the binary decision variable for planning repairs line $l$ during the period $t$, which is one in the repairs and zero for line transmissions out of the repairs, and $W_{l}$ is the number of the time period required by line $l$ for repairs.

According to the relationship (12), the company minimizes its maintenance cost by choosing its decision variable, and specifies (13) the number of repairs required per line. Also, the constraint (14) is for the continuity of repairs. By planning to repair the strategic transmission company, manufacturers can use the conditions that they are using to withdraw a transmission line to prevent capacity constraints. In fact, the planning of repairing the transmission company can affect the physical collusion between the manufacturers. Finally, the relationship between the optimization of social welfare by the independent user of the system is as follows:

$$
\begin{aligned}
& \max S W=\sum_{t=1}^{24} \sum_{j=1}^{J}\left(-0.5 \alpha_{j, t} y_{j, t}^{2}+\beta_{j, t} y_{j, t}\right) \\
& -\sum_{t=1}^{24} \sum_{i=1}^{N}\left(0.5 a_{i, t} q_{i, t}^{2}+b_{i, t} q_{i, t}+u_{i, t} c_{i, t}^{m g}\right) \\
& -\sum_{t=1}^{24} \sum_{l=1}^{L} c_{l, t}^{m l}\left(1-V_{l, t}\right) \\
& S . t . \sum_{i=1}^{N} q_{i, t}=\sum_{j=1}^{J} y_{j, t} \\
& \sum_{i=1}^{N}\left(q_{i, t}^{\max }\left(1-u_{i, t}\right)-q_{i, t}\right) \geq R_{t}^{\min } \\
& y_{j, t}^{\min } \leq y_{j, t} \leq y_{j, t}^{\max } \\
& -F_{l, t}\left(1-v_{l, t}\right) \leq S_{l, n}\left(q_{n, t}-y_{n, t}\right) \leq F_{l, t}\left(1-v_{l, t}\right)
\end{aligned}
$$

In the relationship (15), the maintenance cost of the transmission lines has also been entered. Also, the constraints of the lines are also presented in conjunction (19). With the above formulation, the strategic aspects of maintenance planning for security-related production and scheduling of simultaneous production and transmission repairs, which have not been modeled and investigated, will be analyzed. 
To obtain the final index, the following indices are defined:

$$
\begin{aligned}
& \Delta q_{i, t}{ }^{\text {capacity-withholding }}=q_{i, t}{ }^{p}-q_{i, t}{ }^{e} \\
& \Delta q_{i, t}{ }^{\text {capacity-distortion }}=q_{i, t}{ }^{p}-q_{i, t}{ }^{e} \\
& \Delta \lambda_{n, t}{ }^{\text {capacity-distortion }}=\lambda_{i, t}{ }^{e}-\lambda_{i, t}{ }^{p}
\end{aligned}
$$

In the above relations, $q_{i, t}{ }^{e}$ means the production of units in the $i$ buses and in the period $t$ in the multipolar market, $q_{i, t}^{p}$ is the unit production in the $i$ buses and in the time period $t$ for the market with complete competition, $q_{i, t}{ }^{\prime p}$ is the unit production in the $i$ buses and In the time period $t$ for the market with full competition, with price of the multipolar market, $\lambda_{n, t}$ is the price of the shine $n$ in the period $t, \lambda_{i, t}{ }^{e}$ is the price in the $i$ buses and in the period $t$ for the multipolar market and $\lambda_{i, t}{ }^{p}$ is the price in the $i$ buses and time $t$ for the market with full of competition.

The CCI, which represents the ability to collide in electricity market groups, is defined as follows:

$$
\begin{aligned}
& C C I_{j}=\sum_{i=1}^{N} \frac{\Delta q_{i}^{\text {capacity-distortion }}}{\Delta q_{i}^{\text {capacity-withholding }}} \\
& =\sum_{i=1}^{N}{ }^{q_{i, t}^{p}-q_{i, t}^{e}} / q_{i, t^{\prime p}-q_{i, t}{ }^{e}}
\end{aligned}
$$

$C C I$ shows the group's greater ability to collate in the electricity market. Also, $j$ represents the number of groups that are formed in the electricity market for capacity constraints. 
The problem-solving flowchart and the acquisition of the priority collation list are as follows:

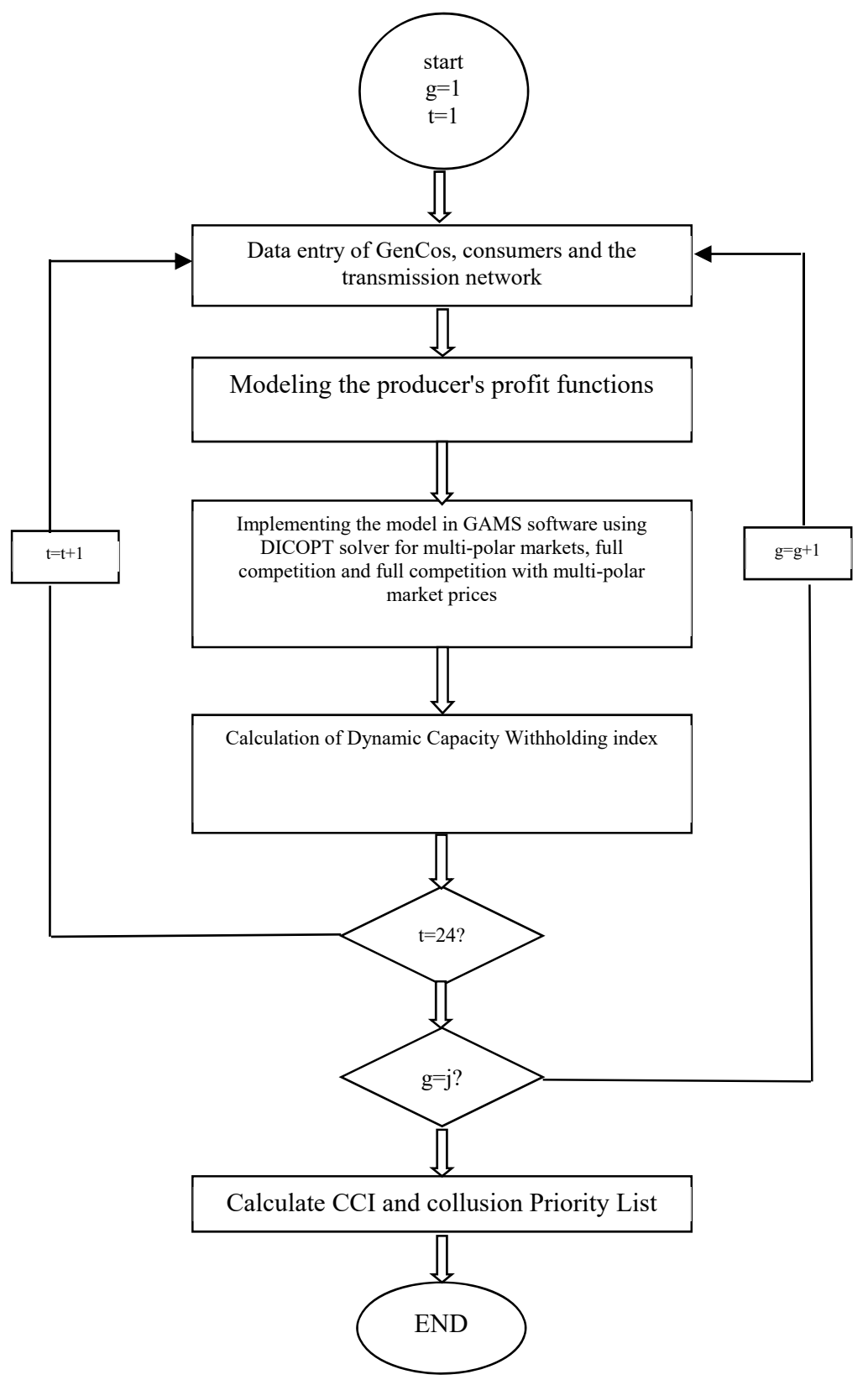

Fig.3. problem-solving flowchart

\section{Numerical Studies by Maintenance Problem of the GenCos}

In this section, the outputs of the priority commands for production units in the IEEE Network's 30\&118-buses are examined and priority list of collusion is obtained.

Transmission network constraints have also been seen in this issue, and production units have a time constraint on entry and exit. Therefore, all studies have been done for a 24-hour period.

\subsection{Numerical Studies For 30-buses IEEE Network}

The parameters of the manufacturers in the IEEE 30-buses system, with the on-off of each unit, and the maintenance and repair costs of the units are as [20]:

the inverse demand curve for each load is that the slope of each inverse of the demand function is chosen to be equal to $35 \$ / \mathrm{MWh}$. The values for the aggregate demand function are as follows: 
Table 1 information on demand curve

\begin{tabular}{|c|c|c|}
\hline Inverse demand function & $\alpha\left(\$ / \mathrm{MW}^{2} \mathrm{~h}\right)$ & $\beta(\$ / \mathrm{MWh})$ \\
\hline$\pi=-\alpha Y+\beta$ & 0.03528 & 45 \\
\hline
\end{tabular}

In this section, the cost of repairs and maintenance of production units is as follows:

Table 2 Repair and maintenance costs for manufacturers in IEEE's 30-buses system

\begin{tabular}{|c|c|}
\hline GenCos & $\$ / h c_{i, t}^{m g}($ \\
\hline 1 & 5500 \\
\hline 2 & 2520 \\
\hline 5 & 2062 \\
\hline 8 & 1240 \\
\hline 11 & 1600 \\
\hline 13 & 1600 \\
\hline
\end{tabular}

In this section, only the planned maintenance and maintenance of the production units for the three 8-hour period is repeated, and according to the outcomes of the CCI, the groups of $\mathrm{j}$ members will be obtained:

Table 3 Collision Priority Groups for manufacturers in IEEE's 30-buses system

\begin{tabular}{|c|c|}
\hline Collision Priority Group & Number of members in the group \\
\hline $1 / 11$ & 2 \\
\hline $1 / 11 / 2$ & 3 \\
\hline $1 / 11 / 2 / 5$ & 4 \\
\hline $1 / 11 / 2 / 5 / 8$ & 5 \\
\hline $1 / 11 / 2 / 5 / 8 / 13$ & 6 \\
\hline
\end{tabular}

All of the above studies are related to the planning of maintenance and maintenance of production units, and repairs of the transmission network have not yet entered into the calculations. For groups of 2 members to 5 members of the CCI index, the priority list for collusion is calculated. It is noteworthy that sometimes groups of 2 members are more dangerous than even a 5-member group, and therefore, ISO should prevent the occurrence of predicted collisions according to the final priority list. Also, by considering a specific clock and comparing the addition of the members of the collocated group, one can identify units with more market power.

\subsection{Numerical Studies For 118-buses IEEE Network}

In this section, all of the standard IEEE 118 system information, and information on maintenance costs of manufacturing units and transmission lines, is based on the IEEE standard 118 system information. The cost of repairing some units is as follows:

Table 4 Repair and maintenance costs for manufacturers in IEEE's 118-buses system

\begin{tabular}{|c|c|}
\hline GenCos & )$\$ / \mathrm{h} C_{i, t}^{\mathrm{mg}}($ \\
\hline 10 & 14361.11 \\
\hline 12 & 5713.23 \\
\hline 25 & 8727.27 \\
\hline 26 & 12175.36 \\
\hline 31 & 10317.85 \\
\hline 45 & 5241.66 \\
\hline 46 & 6106.58 \\
\hline 49 & 8345.09 \\
\hline 59 & 7197.58 \\
\hline 61 & 7312.50 \\
\hline 65.66 & 12902.87 \\
\hline 69 & 22381.56 \\
\hline 80 & 15029.83 \\
\hline 87 & 15600 \\
\hline 89 & 18257.38 \\
\hline 100 & 9498.41 \\
\hline 103 & 5250 \\
\hline 111 & 5288.89 \\
\hline
\end{tabular}


For other units, the maintenance and repair costs are $409 \$ / \mathrm{h}$. These maintenance costs are the same for every 24 hours of the day and the only time-to-hour limitations will affect the logging and exit issues. In this section, with the charts, it is specified at each stage which producers enter the collusion groups. Also, manufacturers with a more complete circle than the rest have more market power and tend to participate equally in all collusion groups. For IEEE's 118-buses network and only with the maintenance and repair of manufacturers, the priority list of collusion is as Fig.4. In this section it is also mentioned that the list of collusion priority is obtained and, in addition, the units for the composition of the collateralisation index are also increased, respectively. As can be seen, in each group of $n$ members, the group that has the most ability to physically collide is brought into the tree. For example, a group of 3 members can be formed in the electricity market, but the group includes 69.89 and 80 members have more potential for physical collusion in the wholesale electricity market and higher prices. Therefore, ISO should prevent the formation of groups in the electricity market according to the priority list.

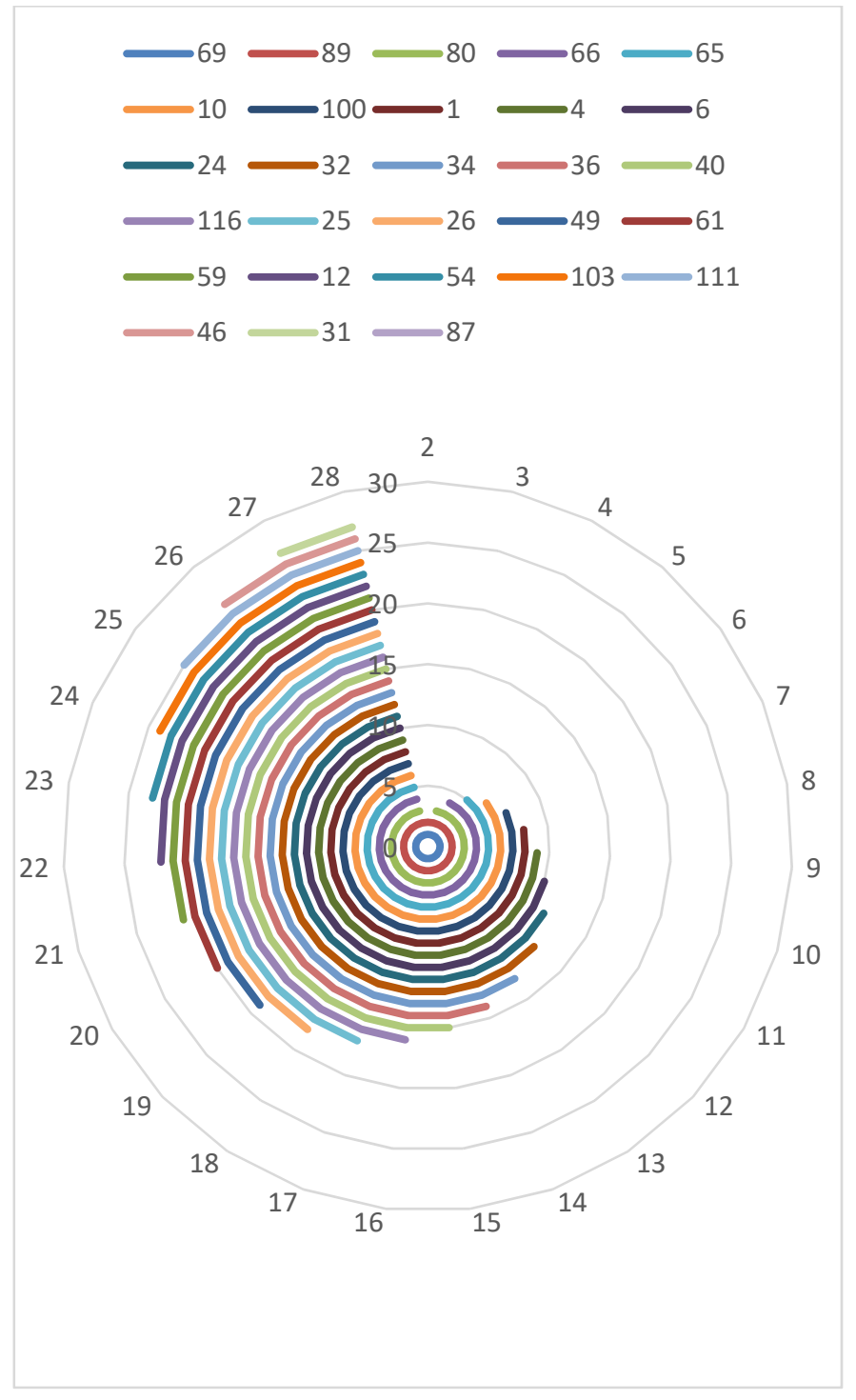

Fig.4. Collision Priority Groups for manufacturers in IEEE's 118-buses system

\section{Numerical Studies by Maintenance Problem of the GenCos and Transmission Network}

In this section, the planning of the transmission network repairs is also included in the studies.

\subsection{Numerical Studies For 30-buses IEEE Network}

In the planning of maintenance of transmission lines, lines 8,9,17,18,31 and 41 are considered as candidate lines for planning of transmission network repairs. The cost of maintenance of transmission lines for all periods of time is $1500 \$ / \mathrm{h}$.

Also, the cost of repairs to manufacturing units is the same as the previous section and Table 2. The collation priority list for the IEEE 30-buses system, with consideration for manufacturing and transfer repairs, is as follows: 
Table 5 Collision Priority Groups for GenCos and Transmission maintenace in IEEE's 30-buses system

\begin{tabular}{|c|c|}
\hline Collision Priority Group & Number of members in the group \\
\hline $1 / 13$ & 2 \\
\hline $1 / 13 / 2$ & 3 \\
\hline $1 / 13 / 2 / 5$ & 4 \\
\hline $1 / 13 / 2 / 5 / 8$ & 5 \\
\hline $1 / 13 / 2 / 5 / 8 / 11$ & 6 \\
\hline
\end{tabular}

In the next eight hours of the day, the power of collusion between the manufacturers is visible and it can be seen at what hours the market power of the players has increased or decreased. This decrease or increase is due to restrictions on the entry and exit of production units, the restriction of the transmission network, the planning of production repairs and transmission lines. At this stage it can be seen that with the addition of network repairs, the transfer list of the priority list of collusion varies greatly. This issue was foreseeable because, due to the new load distribution restrictions as well as network topology changes, the market power of some units decreases more than before or increases.

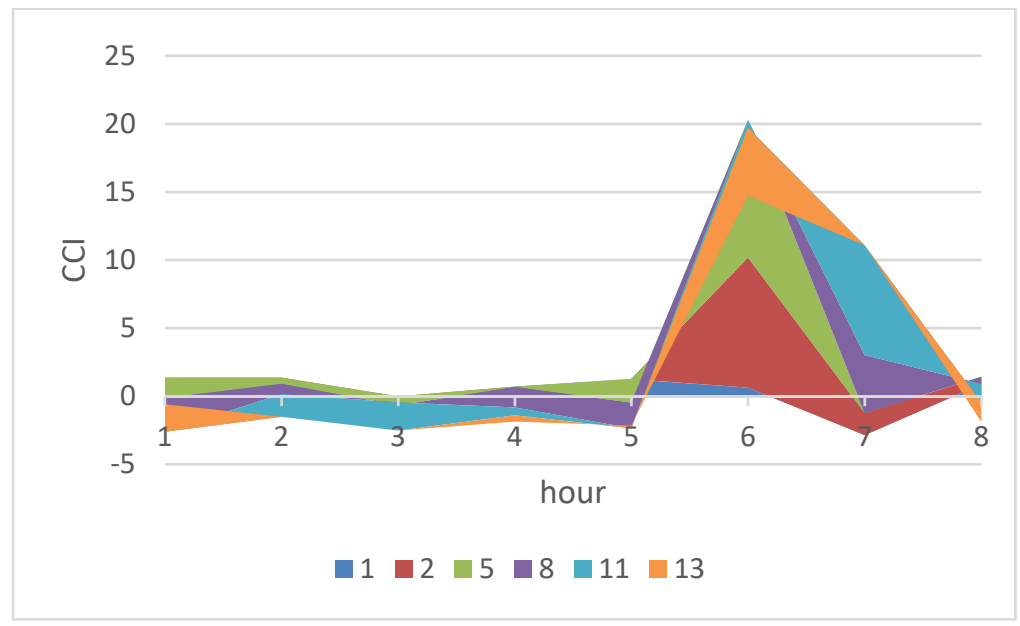

Fig.5. The greatest power of collusion of groups formed in the wholesale electricity market for 8 hours a day in the IEEE 30-bos system

\subsection{Numerical Studies For 118-buses IEEE Network}

In this section, all of the IEEE 118 system bus information, like information on the maintenance costs of production units and transmission lines, is based on the IEEE 118 standard system information. The values for repair costs for some units are shown in Table 4.

For other units, the maintenance and repair costs are $409 \$ / \mathrm{h}$. These maintenance costs are the same for every 24 hours of the day.

The cost of repairing the transmission lines is as follows:

Table 6 Repair and maintenance costs for manufacturers in IEEE's 118-buses system

\begin{tabular}{|c|c|}
\hline Lines & $C_{i, t}^{m}(\$ / \mathrm{h})$ \\
\hline 13 & 4000 \\
\hline 14 & 2500 \\
\hline 35 & 4000 \\
\hline 36 & 2500 \\
\hline 45 & 4000 \\
\hline 67 & 2500 \\
\hline 141 & 4000 \\
\hline
\end{tabular}

The transmission lines are selected as a repair and maintenance candidate in the transfer sector and are charged for the 24-hour horizons. In the following, for this part, the collation priority list is as follows: 


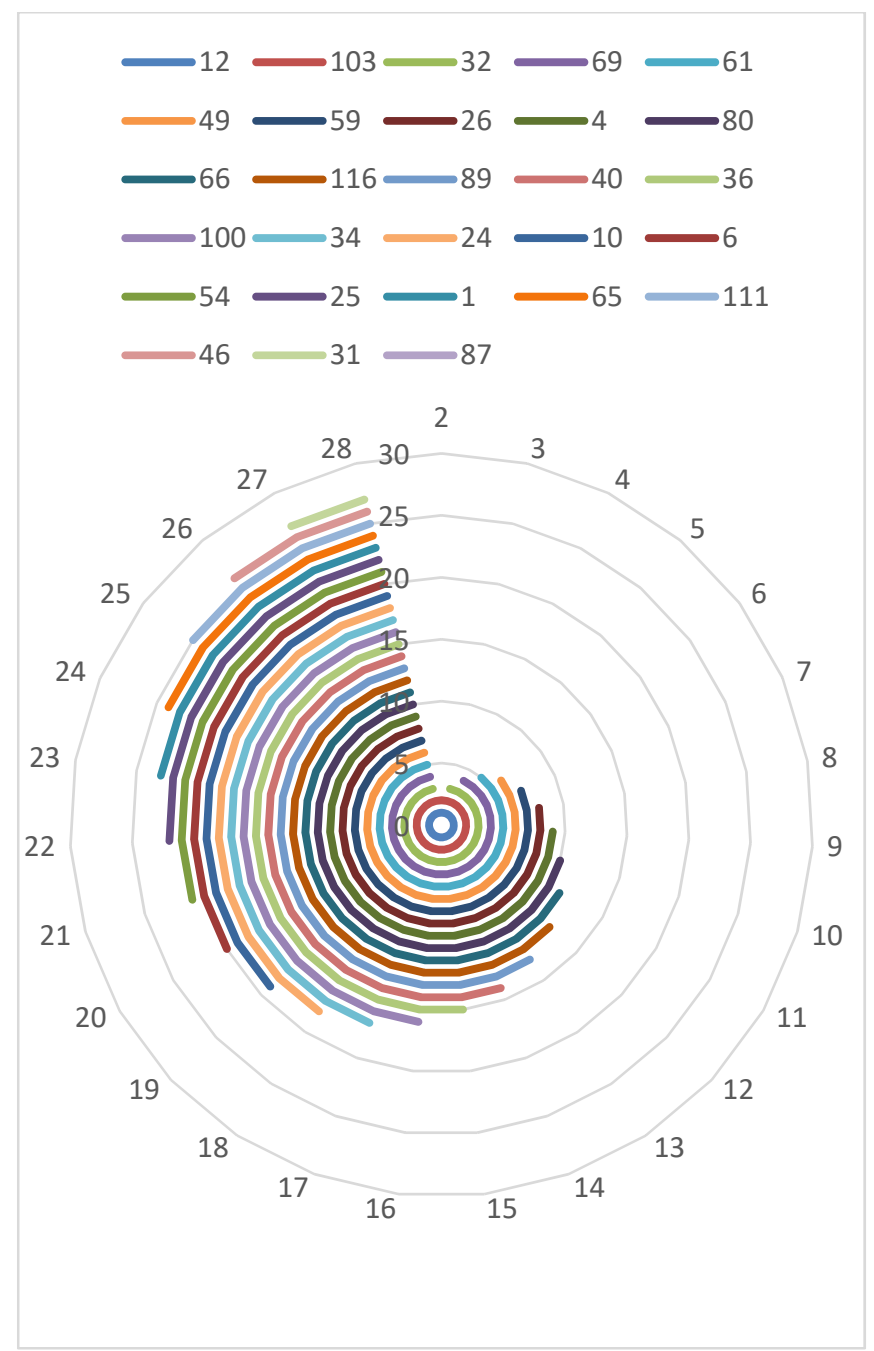

Fig.6. Collision Priority Groups for GenCos and Transmission maintenace in IEEE's 118-buses system

In the figure above, the more complete the circles of the producers, the greater the market power. For example, the market power of the producer 12 in this case is the highest, and thus tends to participate in the electricity market in all the congruent groups. The inner circles participate in more groups than outer circles .For groups of 2 members to 28 members (total number of producers), the collateralisation index is calculated and the collusion priority list is obtained. Also, by considering a specific clock and comparing the addition of the collaborative team members, it is possible to identify units with more market power.

It is unlikely that when repairs of production units and transmission lines will occur together due to the more limited production and transmission, collusion and evaluation index, will be more dangerous to form groups, but it can be more dangerous if decreas the security and stability of the network, so it should be controlled by ISO and pre-set up of these groups. Given the fact that for each number of members, the highest collocations are specified, therefore, ISO should first consider the priority list of collusion, and decide according to the number of members of the groups in the electricity market. Also, with the addition of a member at each stage to the group, can show that where the individual market power of each producer is and how much it can lead to an increase in the price of the wholesale electricity market. For example, in the jump from group 2 to member 3, producer 32 has been added, which suggests that this producer has more market power than 25 other producers and is therefore more likely to enter the collaborative group And this is happening at every stage. 


\section{Conclusion}

In this paper, the Collaborative Priority Scoreboard is derived using the Physical Energy Collaborator Assessment Index, and ISO can prevent the formation of priority groups. This prevents wholesale market price rises and monopolizes the market and, in many cases, ensures the security and stability of the network.

In this paper, after calculating the new index of physical collusion estimation among producers using production and transmission constraints, as well as production and transmission repairs, the list of collusion priority has been obtained. Then the target index was tested on the network of IEEE 30 and 118 buses and the results were presented.When the index of collusion is at its highest level, the reason for this is that at this hour even if one unit is exited, because of the scheduling of repairs and the arrival and departure of units in the previous hours, the network and the system in terms of sustainability and so at this time, ISO should prevent collision with preventive laws. By comparing the addition of the collaborative team members, it is possible to identify units that have more market power. In some cases and for some hours, the two groups have the same collusion power in the wholesale electricity market due to the existence of the same or similar units in terms of market power. Certainly, when the repairs of production units and transmission lines are carried out and due to more production and transmission constraints, the collusion and evaluation index will increase, and thus forming groups will be more dangerous, but from another perspective it is dangerous to form groups that lead to collusion Before rising in price, the security and stability of the network will be severely threatened by the network and is expected to be taken by the control unit and beforehand to form these groups. The resulting graph in the list of priority of collusion is a tree, and at each stage, the producer with higher market power is added to the group and creates a new group of $n+1$ members.

In 118-buses IEEE network, the number of members of the manufacturer is 28 , which can be collapsed in Stage 28 of all members, but from time to time, with the red line of network security, collusion with more members will no longer occur. For example, a collusion will never occur with a group of 28 members, since no other unit will remain for production and pricing.

\section{Refrences}

[1] Stoft S. Power system economics: designing markets for electricity; Wiley-IEEE Press: New York, 2002.

[2] Liu JD, Lie TT, Lo KL. An empirical method of dynamic oligopoly Behavior Analysis in Electricity Markets. IEEE Trans. Power Syst 2006; 5 (2): 499-506.

[3] Bompard E, Wane L, Napoli R. Network constraint impacts on the competitive electricity markets under supply side strategic bidding. IEEE Trans. Power Syst 2006;21(1):160-170.

[4] Badlick R. Electricity market equilibrium models: The effect of parameterization. IEEE Trans. Power Syst $2002 ; 17$ (4): $1170-1176$.

[5] Bompard E, Ma Y, Napoli R, Abrate G. The demand elasticity impacts on the strategic bidding behavior of the electricity producers. IEEE Trans. Power Syst 2007; 2 (1):188-197.

[6] Willems B, Rumiantseva ,Weight H. Cournot versus supply functions: What does the data tell us? Energy Economics 2009.

[7] Niu H, Baldick R, Zhu G. Supply function equilibrium bidding strategies with fixed forward contracts. IEEE Trans. Power Syst 2005; 20 (4): 1859-1867.

[8] Chung TS, Zhang SH, Wong KP, Chung CY. Strategic forward contracting in electricity markets: Modeling and analysis by equilibrium method. IEE Pro. Gener. Transm. Distrib 2004; 151 (2): 141-149.

[9] Day CJ, Hobbs BF, Pang, JS. Oligopolistic competition in power networks: A conjectured supply function approach. IEEE Trans. Power Syst 2002; 17 (3): 597.

[10] Green R.J, Newbery DM. Competition in the British electricity spot market. J. Poliot. Econ. $1992 ; 100$ (5): 929953.

[11] Bautista G, Anjos MF, Vannelli A. Numerical study of affine supply function equilibrium in AC network-constrained markets. IEEE Trans. Power Syst 2007; 22 (3): 1174-1184.

[12] Frezzi, P, Garces, F, Haubrich, H.J. “Analysis of Short-Term Bidding Strategies in Power Markets.”IEEE Power Tech, pp. 971-976, 2007.

[13] Salarkheili, Saeed, and Asghar Akbari Foroud. "Market power assessment in electricity markets: supply function equilibrium-based model." International Transactions on Electrical Energy Systems 23.4 (2013): 553-569.

[14] Baranes, Edmond, Marion Podesta, and Jean-Christophe Poudou. "Mixed bundling may hinder collusion." Research in Economics 70.4 (2016): 638-658.

[15] Mohtavipour, S. S., and A. H. Gholami. "A step toward stable tacit collusion in electricity market." Electrical Engineering (ICEE), 2016 24th Iranian Conference on. IEEE, 2016.

[16] Moiseeva, Ekaterina, Mohammad Reza Hesamzadeh, and Ilias Dimoulkas. "Tacit collusion with imperfect information: Ex-ante detection." PES General Meeting| Conference \& Exposition, 2014 IEEE. IEEE, 2014.

[17] Tellidou, Athina C., and Anastasios G. Bakirtzis. "Agent-based analysis of capacity withholding and tacit collusion in electricity markets." IEEE Transactions on Power Systems 22.4 (2007): 1735-1742.

[18] Chen H, Wong KP, Chung CY, Nguyen, DHM. A coevolutionary approach to analyzing supply function equilibrium model. IEEE Trans. Power Syst 2006; 17 (3):1019- 1028.

[19] Zhang SX, Chung CY, Wong KP, Chen, H. Analyzing two-settlement electricity market equilibrium by coevolutionary computation approach. IEEE Trans. Power Syst 2009: 8 (3): 1155-1164.

[20] Salarkheili Saeed, and Mehrdad Setayesh Nazar. "Capacity withholding analysis in transmission-constrained electricity markets." IET Generation, Transmission \& Distribution10.2 (2016): 487-495.

[21] Fabra, Natalia, Toro, and Juan. "Price War and Collusion in the Spanish Electricity Market." International Journal of Industrial Organization, vol. 23, pp. 155-181, 2005.

[22] Liu Dun-nan, He Guang-yu, Li Rui-qing, and Chen Xueqing. “Analytical method of Supplier's Behaviors in Electricity Market." IEEE Conference on Power Systems Conference and Exposition, vol. 2, pp. 881-885, 2004.

[23] Xiaohong Guan. "Gaming and Price Spikes in Electric Power Markets and Possible Remedies." IEEE International Conference on Power System Technology, vol. 21, pp. 58, 2002. 
[24] Liu Dun-Nan, Wu Ya-Guang, Jiang Xiao-Liang, He Guang-Yu and Zhang Hua-Qing, "Key Performance Indices To Monitor Bidding Behaviors In Electricity Market.” IEEE Power Systems Conference and Exposition (PSCE '06), pp. 1156-1161, 2006.

[25] Wu Wei-Ku, and Wen Dan-Hui. "Preventing Tacit Collusion in Chinese Electricity Reform," IEEE International Conference on Service Systems and Service Management, pp. 1-5, June 2007.

[26] Frezzi, P, Garces, F, and Haubrich, H.J. "Analysis of Short-Term Bidding Strategies in Power Markets." IEEE Power Tech, pp. 971976, 2007.

[27] Salarkheili, Saeed, and Asghar Akbari Foroud. "Market power assessment in electricity markets: supply function equilibrium-based model." International Transactions on Electrical Energy Systems 23.4 (2013): 553-569.

[28] Tellidou, A.C, and Bakirtzis, A.G. "Agent-Based Analysis of Capacity Withholding and Tacit Collusion in Electricity Markets", IEEE Transactions on Power Systems, vol. 22, pp. 17351742, 2007.

[29] Feng Kong, and Hongyan Liu. "Analysis of Market Power of Oligopolistic Generators." IEEE International Conference on Services Systems and Services Management, vol. 1, pp. 2002.

[30] Cau, T. D. H, Anderson, and Edward J. "A Co- Evolutionary Approach to the Tacit Collusion of Generators in Oligopolistic Electricity Markets: Piecewise Linear Bidding Structure Case.” IEEE Congress on Evolutionary Computation, vol. 4, pp. 2306-2313.

[31] Cain, M.B, and Alvarado, F.L. "The Impact of Uncertainty on Incentives to Collude in Electricity Market "IEEE International Conference on Probabilistic Methods Applied To Power Systems, pp. 433-438, 2004.

[32] Anderson, E. J, and Thai DH Cau. "Implicit collusion and individual market power in electricity markets." European Journal of Operational Research 211.2 (2011): 403-414.

[33] Sapio, Alessandro, and Nicola Spagnolo. "Price regimes in an energy island: Tacit collusion vs. cost and network explanations." Energy Economics 55 (2016): 157-172.

[34] Aliabadi, Danial Esmaeili, Murat Kaya, and Güvenç Şahin. "Determining collusion opportunities in deregulated electricity markets." Electric Power Systems Research 141(2016): 432-441.

[35] Dijkstra, Peter T, Marco A. Haan, and Machiel Mulder. "Industry structure and collusion with uniform yardstick competition: theory and experiments." International Journal of Industrial Organization 50 (2017): 1-33.

[36] Schubert, Jens. "The impact of forward contracting on tacit collusion: Experimental evidence." Journal of Economic Behavior \& Organization 119 (2015): 109-123.

[37] Baranes, Edmond, Marion Podesta, and Jean-Christophe Poudou. "Mixed bundling may hinder collusion." Research in Economics 70.4 (2016): 638-658.

[38] Baranes, Edmond, Marion Podesta, and Jean-Christophe Poudou. "Mixed bundling may hinder collusion." Research in Economics 70.4 (2016): 638-658.

[39] Nazir, M. S, and F. D. Galiana. "Fast computation of equilibrium market outcomes considering tacit collusion." European Energy Market (EEM), 2012 9th International Conference on the. IEEE, 2012.

[40] Shafie-khah, M, et al. "Regulatory support of wind power producers against strategic and collusive behavior of conventional thermal units." European Energy Market (EEM), International Conference on the. IEEE, 2016.

[41] Mohtavipour, S. S, and A. H. Gholami. "A step toward stable tacit collusion in electricity market." Electrical Engineering (ICEE), 2016 24th Iranian Conference on. IEEE, 2016.

[42] Moiseeva, Ekaterina, Mohammad Reza Hesamzadeh, and Ilias Dimoulkas. "Tacit collusion with imperfect information: Ex-ante detection." PES General Meeting| Conference \& Exposition, 2014 IEEE.

[43] Tellidou, Athina C, and Anastasios G. Bakirtzis. "Agent-based analysis of capacity withholding and tacit collusion in electricity markets." IEEE Transactions on Power Systems 22.4 (2007): 1735-1742. 